\title{
Digital libraries: barriers or gateways to scholarly information?
}

\author{
Alex Byrne*
}

\begin{abstract}
Unprecedented desktop access to scholarly information has been made possible by the introduction of digital libraries. The powerful combination of digital publications, specialist and generalist databases, sophisticated search systems and portals enables scholars and students to rapidly examine a great variety of the literature in their own disciplines and those new to them. Access is available globally 24 hours a day without geographical limitation.

But that access is not without limitations. It is limited by the availability of reliable and affordable information and communication technologies. It is limited to those scholars and students who are affiliated with organisations which have the money and skills to provide access. It is limited to those who are literate, information literate and have a command of the major languages of commerce and scholarship (English in particular). In addition, contractual and other bounds imposed by vendors exclude many potential users. In combination, these limitations inhibit many scholars and students from using digital scholarly information and can increase the marginalisation of the already marginalised including, especially, indigenous peoples. This contradiction between access for some and marginalisation for many poses many challenges for libraries.
\end{abstract}

The paper has been adapted from a paper presented at the 24th Conference of the International Association of Technological University Libraries "Libraries and Education in the Networked Information Environment", June 2-5, 2003, Middle East Technical University, Ankara, Turkey.

\footnotetext{
* Biographical note: Alex Byrne chairs the Committee on Free Access to Information and Freedom of Expression (FAIFE - http://www.faife.dk), is a member of the Governing Board and was recently elected President-elect of the International Federation of Library Associations and Institutions (IFLA http://www.ifla.org). He is the University Librarian and a Deputy Chair of the Academic Board at the University of Technology, Sydney in Australia where he can be contacted on Tel +61 29514 3332, Fax +61 29514 3331, alex.byrne@uts.edu.au.
} 


\section{The digital library}

A new digital paradigm for the library has been developed (Berring 1993) through the creation of bibliographic, factual and fulltext databases, the application of powerful inquiry technologies, and their linkage through complex communications networks. The model is referred to as the 'digital library', 'virtual library' or even 'cybrary' ${ }^{\text {. In }}$ its narrowest sense the digital or virtual library can be considered to be merely an "online repository of electronic texts" (Ince 2001) or "electronic stock of information which can be accessed via databases" (Dictionary of library and information management 1997). Both of these definitions focus on storage and access to content but miss the other dimensions of a library. "A system providing the services of a library in digital form" (Johnston et al. 2000) offers an alternative definition which better describes a library operating electronically.

The hybrid library encompasses print and electronic formats brought together in an integrated information service, accessed via a combination of local and remote electronic gateways (HyLiFe Programme 2001). It includes print information sources alongside the electronic offering organised access to both. Explored by means of a number of projects sponsored through the eLib program in the UK, the hybrid library has been viewed as a transitionary stage in a progression from physical to wholly digital libraries: a stage which likely to last for a considerable period because of the cost of conversion from print (Brophy 2001).

At the University Library of the University of Technology, Sydney, the digital library includes the following elements:

\section{Integrated content provision}

- A major emphasis on digital resources including a wide range of aggregations, delivering a total of some 40,000 titles in 2003 (including some which are offered via multiple sources).

- Integration of the delivery of databases, ejournals and ebooks with print by providing hot linked records in the catalogue using the AutoCat software.

- Crossfile searching and linking to full text and other services using the Metalib/SFX software (which is locally branded as 'SuperSearch').

- Electronic delivery of digitised Reserve and Course Materials linked to the eLearning software Blackboard (branded as UTSOnline).

- Development of an electronic publishing arm for the university, UTSePress.

- Participation in the Australian Digital Theses program.

\section{Support \& training}

- Development of online real time reference services, initially using email and progressing to the eGain/LSSI software (branded as ALIVE).

\footnotetext{
1 "The University of Queensland Library uses the term Cybrary to describe its integration of cyberspace and physical space."
} 
- Collaboration with the University of Strathclyde in Glasgow, Scotland, and Curtin University of Technology in Perth, Western Australia, to provide 24x7 reference service.

- Online information skills learning integrated with UTS BELL generic skills program.

- Provision of productivity software (including Microsoft Office products) through the Learning Commons.

- Creation of websites and e zines to promote the services and provide value added services (including a Chinese language website).

\section{Library effectiveness}

- Knowledge management support for library practice and administration through a range of services on a staff only site.

- Creation of websites to promote interlibrary collaboration (including those for the group of university librarians in the state of New South Wales, UNISON, and for the Libraries of the Australian Technology Network).

This list is not comprehensive but shows a range of ways in which the characteristics of one university library are being reflected in its extension into a digital library. The features extend well beyond the "electronic stock of information" to encompass as many as possible of the features of a university library but presented and delivered electronically.

\section{The contradictions}

As is recorded in a wealth of articles and books in the professional literature, access to the powerful combination of digital publications, specialist and generalist databases, sophisticated search systems and portals has created unprecedented desktop access to scholarly information. Together they have provided a digital library which enables scholars and students to rapidly examine a great wealth of the scholarly literature in their own disciplines and those new to them. Access is available globally 24 hours a day without geographical limitation.

Well, that is the promise. But the access is not without limitations. It is limited by the availability of reliable and affordable information and communication technologies. It is limited to those scholars and students who are affiliated with organisations which have the money and skills to provide access. It is limited to those who are literate, information literate and have a command of the major languages of commerce and scholarship and, of course, English in particular. In addition, contractual and other bounds imposed by vendors exclude many potential users.

Let us explore some of these limitations.

We can first consider three domains in which preconditions must be satisfied if comprehensive access to digital scholarly information is to be obtained without 
temporal, spatial or other restrictions. The domains are infrastructure, education and skills, and content. Each has multiple levels at which barriers to access can emerge.

\section{Infrastructure}

While a wealthy individual (or one with military or mining company support) might use a solar powered laptop with a satellite uplinked broadband connection to access a digital library, this method is likely to be feasible for very few scholars or students, an particularly those in developing countries. Infrastructure is thus essential and must include basic infrastructure, telecommunications, computers and software.

Without the basic infrastructure of reliable electricity supplies, physical access to set up services and suitable buildings (universities, libraries, telecentres, schools) in which to establish them, it is very difficult to provide or to access digital services. This is an immediate problem in Afghanistan and East Timor, both devastated by conflict, but also in poor and remote areas of many countries. It immediately inhibits the provision of access to most indigenous peoples who tend to live in the poor and remote areas.

Telecommunications infrastructure is obviously vital and has many choke points at which services can become unavailable through lack of capacity, unreliable service, unsustainable cost, corporate policy or political control. While users in advanced nations are seeing ever decreasing Megabyte charges due to over capacity on intercontinental cables and the implementation of high bandwidth domestic and international fibre networks, many in poorer countries find international access costs too high and suffer very limited domestic bandwidth (Greenspan 2002). Inadequate distribution networks deprive many parts of many countries of access, especially poorer districts of cities and poor and remote rural regions. In combination these deficiencies result in frequent service drop outs and an inability to use advanced services. Students in US and other Western campus dorms may be breaching copyright by downloading pirated copies of the latest blockbuster movie but their counterparts in many countries cannot access basic HTML or text based services.

There is another dimension to these deficiencies. They provide opportunities for corruption. Powerful national and international corporations in league with governments can decide which areas to service and who will gain the profits. Communities and groups can be marginalised through denial of access or prices beyond their means - marginalisation which may be deliberate or 'collateral damage' in the pursuit of power and profits. This marginalisation again impacts on the already marginalised. It broadens the divide between the advantaged and those already facing disadvantage, extending disparities based on gender and ethnicity.

For repressive governments, the choke points also offer means for seeking to prevent access to politically unacceptable information and for surveillance of users, as has been demonstrated in China and other countries (Reporters sans frontières 2003). The licensing of Internet service providers (ISPs) provides another point of control. Few can mean limited choice of service with a lack of advanced services and little price competition which can again prevent usage by many people. However, it is the control 
aspect that is perhaps of greatest concern in regard to ISPs since it is a level at which filtering can be easily imposed. Further, users' traffic can be monitored and easily linked to their identities recorded in the ISPs' billing systems. Similar concerns apply to common access Internet facilities in Internet cafés, public libraries and telecentres: they offer little privacy and thus offer opportunities for surveillance and repressive action as has recently been seen in China.

Access to computers constitutes the next level which is essential to enable use of the digital library. Whether it be from a common access Internet facility, home, school, university or workplace, ready access to a computer which reasonable capabilities is essential. Without enough computers, it is impossible to get sufficient access time. Without adequate memory, speed and storage, it is impossible to open, download or use electronic scholarly information. These problems can be compounded by ageing hardware and lack of technical support.

Up to date and efficient software is equally important. Proprietary software may be too expensive and lack compatibility with other systems. Open source software may not be readily available. In addition, software may be unsuitable for national or local conditions because it implements a North American or European solution and fails to accommodate local considerations. It is unlikely to be available in languages other than the principal European languages, and especially English, although some library systems and other software do provide user interfaces in a variety of languages (Gonzales 2003).

Both hardware and software present other problems. Although much hardware is manufactured and software is shrink-wrapped in poorer countries, the centres of technological development, the owners of the intellectual property and the destinations of cash flows are located principally in North America and Northern Europe. Dependence on industry standard computers and programs thus impoverishes and disempowers the residents of poorer countries - Ireland and Finland are probably the only countries which have been able to renew themselves as major centres of high technology development, but both are located in Northern Europe. The high costs and foreign exchange requirements put the technologies out of reach of many and offer opportunities for corruption to corporations and government officials.

\section{Education \& skills}

But all the equipment, connectivity and software in the world are useless without the skills to use it. Basic computers skills are of course necessary but not sufficient. Use of scholarly information demands high levels of literacy and the development of information literacy. Those who do not have the opportunities to develop the necessary panoply of skills are unable to use digital scholarly information effectively. They lack the codes to open the digital library.

Advanced skills are required to manage systems and to be able to create and make available information. Without those abilities, scholars remain consumers and their creations are locked out of contemporary scholarly communication. 
Language, however, is the most important ability. Other languages are catching up to English and are doing so at a faster rate than was predicted (Pastore 1999). Table 1 indicates that, at present, the distribution of languages of Internet users broadly mirrors wealth. This high level picture, however, hides considerable variation. For example, German and Japanese speakers are more likely to use the Internet than the sizes of their economies would predict, French, Spanish, Arabic and Chinese less so. It does make it clear that many language users are invisible on the Internet including those from South Asia, all of Africa and Indonesia as well as the speakers of indigenous languages.

\section{TAKE IN TABLE 1}

The dominance of a few languages on the Internet continues to privilege those users who are fluent in the dominant languages. Conversely, it marginalises those without sufficient familiarity. This is of course not unique to digital information: the predominant languages of international scholarly communication have been the major European languages and English has become progressively more dominant during the twentieth century. However, the meshed systems of content-metadata-search-access which make digital information systems so powerful also make them highly language dependent, which disables those without high levels of competency in the languages of the systems (or language, since it is usually English) as well as the languages of scholarship. Even the most highly educated scholar can be incapacitated. The least educated, among whom many indigenous peoples are over represented, often speak English or other 'international' languages as a third, fourth or fifth language and are thus disadvantaged from the outset.

\section{Content}

Lack of language ability can also make it very difficult to contribute to the international scholarly literature. Publications in little understood languages are inevitably ignored unless translated or cited by publications in the major languages. Without language it may be impossible to adequately convey concepts within their cultural context. Insularity in language can thus engender insularity in understanding. In scholarly communication it can lead to ignorance of important findings and knowledge. The dominant can conversely be ignorant because of their linguistic incompetence.

Emphasis on the leading scholarly publications is an inevitable consequence of the concerns both for quality in research and scholarship and to obtain the rewards from it. However, it has the effect of privileging those in the better recognised and richer institutions and countries: it is easier for them to publish than for those outside the mainstream. Perspectives from the periphery are relatively seldom published.

This hegemony has meant that most of the literature which is accepted to be scholarly in relation to indigenous peoples is written about indigenous peoples rather than by them. Feminist discourse has gone a long way to correct gender based disparities in scholarship but that success only emphasises the imbalance in indigenous scholarship and among others whose perspectives have been ignored or appropriated. The IFLA 
Statement on Indigenous Traditional Knowledge (http://www.ifla.org/III/eb/sitk03.html) is a step towards the recognition of library responsibilities in this area but the statement needs to be revised a systematic strategies need to be developed and implemented both by libraries and the other actors in the processes of scholarly publication.

The development of digital scholarly communication has amplified these differences. While digital publication and distribution can be much cheaper than print and global access is available at a few clicks on the World Wide Web, recognition of new and peripheral scholarly publications is paradoxically as difficult as it always was, if not more difficult. This is because the significant levels of expertise and investment in the means of production and distribution have led to aggregation of higher status journals and databases.

Many other issues relating to digital content stem from ownership. The transfer of the control of titles from academy and professional presses to commercial publishers has led to the commodification of scholarly literature. The consequential, significant and sustained increases in the costs of subscription or access over the last thirty years has put most high status scholarly journals out of reach of many university libraries and most individual scholars. Many university and research libraries in developing countries have been unable to purchase a journal for many years: they depend on donations. In richer countries the situation is not so dire but there can be very few academic and research libraries that are able to meet the inexorably rising costs. The problems have again been exacerbated by the move to electronic scholarly information which has significantly raised the entry fee from the price of a single subscription to the price of at least a minimal aggregated set (in addition to the costs in infrastructure and skills discussed above). For those with the entry fee, it has often been possible to obtain access to more publications for the same or less cost, those without the entry fee have been shut out completely.

Since most scholarly literature is necessarily imported in most countries, its purchase requires both funding and foreign exchange in some of the world's strongest currencies (US dollar, UK pound, Euro) which is very difficult for universities and their libraries to obtain. For Australian university libraries, it means some $80 \%-90 \%$ of resources expenditure goes overseas - even though our scholars produce some $2 \%$ of the world scholarly literature. In some countries, such dealings offer opportunities for corruption: corrupt import-export companies dealing with corrupt officials.

The control obtained over scholarly intellectual property by major publishers acts as a significant barrier to widespread access. It limits the use of interlibrary loans, copying for student use and republication. This is not to decry the benefits of a balanced intellectual property regime but to describe some of the consequences of current directions in the law in most countries (under WIPO and WTO guidance). The harm to scholarship from current trends in intellectual property law is not inherent in the principles of intellectual property but has two roots. One is the narrowing of the public good: tighter conditions for fair use and postponement of succession to the public domain. The other is greed: the desire to obtain a continuing commercial return from scholarly publication (even though the commercial publishers have invested only in its 
distribution, not in its creation). This has shifted the emphasis in scholarly information from communication between scholars to profit for publishers and distributors.

Again, these trends have been exacerbated in the digital environment. In particular, the move to licensing access rather than selling copies has significantly shifted power to the licensor. Access is now tied to subscription. Where purchase of printed issue of journal provided enduring access to that issue, subscription to a digital issue offers access only while the subscription is maintained and the issue continues to be available on the licensor's server. Although some licences allow for 'perpetual' access to the material to which a library has subscribed, the feasibility of this in the longer term has not yet been able to be tested. But there is another aspect. Having bought the printed issue, the library or individual could keep it, sell it or donate it. Many libraries and scholars have passed serial runs to newly established libraries and those in poorer countries. This is no longer possible in the digital library, the licences are not transferable.

And, finally, in this long list of professional challenges created for us by the digital library, is its vulnerability to control. Censorship can be and is applied to printed materials, although university libraries have often been exempted as in the case of South Africa under apartheid (Merrett 1994). In the digital environment, filtering and surveillance as described above can be surreptitiously or openly applied with chilling effect on scholarship. Publishers, too, find it easier to apply post publication censorship than in the print environment, as was demonstrated in the recent case concerning the Elsevier title Human Immunology (Krimsky 2002). A paper on the genetic identity of Mediterranean peoples (Arnaiz-Villena et al. 2001) was removed from the database because of complaints rather than challenged through the normal scholarly processes. Fortunately, this case had a beneficial result in that the outcry resulting from the suppression led to Elsevier adopting a new policy in Feb 2003: the article was restored to the database and marked "RETRACTED". Nevertheless, the case illustrated the potential for suppression by removal from a database - a process which was much harder to achieve with printed publications.

\section{Systemic issues}

Some themes emerge from the discussion of barriers to achieving the promise of the digital library. The first is the intertwined effects of commodification, corporate control and aggregation. They have led to further marginalisation of scholars outside the mainstream by making it more difficult for their scholarship to be published and recognised. The balance in intellectual property has shifted from protecting the creator's interests to protecting those of the owner, for scholarly communication this has shifted the emphasis from communication to profit. Digital publication facilitates this process by changing the business model from purchase to lease.

These trends have amplified the disadvantages already suffered by many libraries and scholars, especially in poorer countries. They cannot afford access to high priced aggregations of scholarly publications nor can they or their countries afford to invest in the necessary ICT infrastructure. Previously a superseded backset of a journal could 
have provided useful sources for a student and for research training, but nothing is available now without subscription.

In the digital environment, language has become much more important. Without good knowledge of the major languages of scholarship and of English in particular, it is impossible to both use the systems and read and comprehend the literature. Education and skills have also become more important especially computer skills and information literacy. Without those competencies, the systems can only be used ineffectively and the student or researcher is unable to access the literature.

Governments have found new opportunities to exert control with the move to digital access to scholarly information. In the print world, governments could stop local publication, block imports, intimidate and arrest scholars, suppress students. They can still do all of these things but they also have new means available for repression. Surveillance through ISPs, Internet cafés and at other points allows communication to be monitored but also patterns of searching and access to information. Filtering can be imposed for moral or political purposes, blocking access to research resources along with other materials. Pressure can be applied to commercial interests to provide sanitised services into a nation, as in the agreement between the Chinese Government and Murdoch in regard to satellite television news services.

Opportunities for corruption have multiplied similarly. Although most lie outside the immediate areas of university and research libraries, they can have effects on the cost and feasibility of providing access to digital resources. Libraries are unlikely to have the political clout or the financial resources to obtain favourable treatment.

For indigenous peoples, these strictures interact and multiply. As was mentioned above, many live in poorer and more remote regions and are marginalised economically, educationally and linguistically. In addition, many are the subjects of social and, sometimes, government sponsored discrimination. In combination, these factors prevent indigenous peoples from exploiting scholarly information and even more from contributing to it.

\section{What is to be done?}

These contradictions between the technical possibilities and the economic, educational and infrastructural limitations pose many challenges for libraries, and especially technological university libraries, if we are to take advantage of the potential of the digital library. There are many issues to address. Key questions include:

- How can we ensure that our faculty and students will have the access they need to the world's scientific, technological and other literature?

- How can we help them develop the skills to use that literature effectively?

- How can we work together to create the conditions for successful implementation of digital libraries? 
Much is being done but it seems doubtful that information inequality will be overcome without a revolutionary change in priorities at all levels of government.

Returning to the three domains discussed above.

\section{Infrastructure}

The World Summit on the Information Society (WSIS) to be held in Geneva in December 2003 and Tunis in November 2005 aims to address the digital divide (WSIS 2003). Its draft Declaration of Principles and Action Plan attempt to identify targets to be achieved to improve access by those in developing nations. IFLA is engaging with the WSIS preparatory process in order to ensure that the issues of information inequality will be given prominence.

Besides systemic approaches, initiatives by individual libraries or consortia can assist. The National University of East Timor Library, for example, has benefited from the assistance of Australian librarians and libraries (Blood 2001).

Standards are a key issue. Those of us who are in a position to do so can advocate the use of open source software and other open standards. The UTS Library, for example, has pushed Innovative Interfaces Inc to port its library system to Linux and we are using Linux as an operating system for our servers.

\section{Education \& Skills}

This is a broad and multi-layered issue. IFLA and others have sought to bring it to the attention of the WSIS but it needs concerted international action. The development of information literacy standards in a number of countries is a vital step but this remains a significant obstacle throughout the world.

Support by the Soros Foundation for the training for library and information professionals in Eastern Europe and the Caribbean has been invaluable. It has complemented the long standing programs of the IFLA Advancement of Librarianship Program and the IFLA Regional Offices in Africa, Asia and Latin America.

The issues of language are particularly difficult. While the Internet is being used to create virtual language communities which have the potential to sustain threatened languages, the common languages of discourse are likely to become the major commercial languages including English, Chinese, Spanish, French and Arabic. However, for scholarly communication it is difficult to see any rivals to English.

\section{Content}

The initiatives by BioMed, Soros and others are making it possible for university and research libraries in the least developed countries to access some of the scholarly literature. This is not enough but it is a good start. 
Similarly, the work of SPARC, Highwire Press and others is challenging the established model of high priced scholarly journals. Their high quality publications are available at reasonable cost especially in electronic form. Some of us will be able to emulate the example of those pioneers, others can support the initiatives by subscribing to the new publications and promoting them to our faculty.

Again, the work over many years of the IFLA Sections and Core Programmes has provided much of the groundwork for collaboration. It has been particularly significant in such areas as standardisation, interlending and the other work of the Universal Availability of Publications program. Their work and that of others concerned with the development and implementation of standards have laid the foundations for many current achievements.

\section{Conclusion}

In attempting to address the issues raised above and other questions, libraries help advance the development of their societies and economies. Not all of the issues come within our ambit but all affect our work so it is important that we understand the issues and seek ways of addressing them. Within our libraries we can implement new technologies which facilitate access for our users. Collectively we can pursue collaborative approaches to purchasing, service development, standards and principles.

However, the position of indigenous peoples is particularly challenging. The interaction of the factors described in this paper has heightened impact on them. While the potential ubiquity of digital access to scholarly information has the potential to assist self determination and the fight against disadvantage, indigenous peoples are among the least able to use it or to contribute to it. This poses major challenges for the global library and information community.

\section{References}

Arnaiz-Villena, A, Martinez-Laso, J, et al. 2001, 'The correlation between languages and genes: the Usko-Mediterranean peoples', Human Immunology vol. 62, pp. 10511061.

Berring, RC 1993, 'Future librarians', in Future libraries, RH Bloch and C Hesse, eds., Berkeley, University of California Press, pp. 94-115.

Blood, J 2001, APHEDA Library Project - National University of East Timor, August 2001, [Dili], APHEDA. http://untl.labor.net.au.

Brophy, P 2001 The library in the twenty-first century, London, Library Association Publishing.

Dictionary of library and information management, 1997, Peter Collin Publishing. http://www.xreferplus.com/entry/1042016. 
Global Reach 2003, Global Internet statistics (by language), 30 September 2002. http://www.glreach.com/globstats.htm.

Gonzales, EJ 2003, 'Language limits confront Latinos on Internet', IMDiversity. http://www.imdiversity.com/villages/hispanic.

Greenspan, R 2002, 'China pulls ahead of Japan', CyberAtlas, 22 April 2002. http://cyberatlas.internet.com.

HyLiFe Programme 2001, The HyLiFe Hybrid Library Toolkit, University of Newcastle, UK. http://hylife.unn.ac.uk/toolkit/.

Ince, D 2001 A dictionary of the Internet, Oxford Reference Online, Oxford, Oxford University Press. http://www.oxfordreference.com/.

Johnston, R, Gregory, D, et al. 2000 The dictionary of human geography, xreferplus, Oxford, Blackwell. http://www.xreferplus.com/entry/734102.

Krimsky, S 2002, 'For the record [Human Immunology]', Nature genetics vol. 30, p. 139. http://genetics.nature.com.

Merrett, C 1994 A culture of censorship: secrecy and intellectual repression in South Africa, Cape Town, David Philip \& University of Natal Press.

Pastore, M 1999, 'The language of the web', CyberAtlas, 6 July 1999. http://cyberatlas.internet.com.

Reporters sans frontières 2003, CHINA: INTERNET IS A TRAP, 12 May 2003. http://www.rsf.org/article.php3?id_article=6793.

WSIS 2003, 'World Summit on the Information Society', International Telecommunications Union. http://www.itu.int/wsis. 
TABLE 1

Major languages of Internet users 30 September 2002 (Global Reach 2003)

\begin{tabular}{|c|c|c|c|}
\hline & $\begin{array}{c}\text { Internet access } \\
\text { (M) }\end{array}$ & $\begin{array}{c}\% \text { world online } \\
\text { population }\end{array}$ & $\begin{array}{c}\% \text { world } \\
\text { economy (GDP) }\end{array}$ \\
\hline English & 230.6 & 36.5 & 33.4 \\
\hline $\begin{array}{l}\text { European languages } \\
\text { (excl English) }\end{array}$ & 224.1 & 35.5 & 33.9 \\
\hline Asian languages & 179.4 & 28.3 & $\begin{array}{r}28.0 \\
\text { (approx) }\end{array}$ \\
\hline
\end{tabular}

